\title{
Perspective
}

\section{Importance of Studying the Contributions of Early Adverse Experience to Neurobiological Findings in Depression}

\author{
Christine Heim', Paul M Plotsky' and Charles B Nemeroff*, I \\ 'Department of Psychiatry and Behavioral Sciences, Emory University School of Medicine, Atlanta, USA
}

\begin{abstract}
Almost four decades of intensive research have sought to elucidate the neurobiological bases of depression. Epidemiological studies have revealed that both genetic and environmental factors contribute to the risk for depression. Adverse early-life experiences influence neurobiological systems within genetic limits, leading to the neurobiological and behavioral manifestations of depression. We summarize the burgeoning evidence concerning a pre-eminent role of early adverse experience in the pathogenesis of depression. The available data suggest that (I) early adverse experience contributes to the pathophysiology of depression, (2) there are neurobiologically different subtypes of depression depending on the presence or absence of early adverse experience, likely having confounded previous research on the neurobiology of depression, and (3) early adverse experience likely influences treatment response in depression. Classification of depression based on developmental and neurobiological features will likely considerably improve future research in the field of depression, and might lead to optimized treatment strategies that directly target different neurobiological pathways to depression. Neuropsychopharmacology (2004) 29, 64I-648, advance online publication, 3 March 2004; doi: I 0. I 038/sj.npp. I 300397
\end{abstract}

Keywords: CRF; HPA axis; early life trauma; depression; anxiety

\section{INTRODUCTION}

The causes of depression are still obscure. In the quest for the biological bases of depression, numerous studies have identified multiple neuroendocrine, neurochemical, and neuroanatomical changes in patients with major depression. Many of these changes affect neuronal circuits that are known to be critically involved in modulating stress and emotion (Arborelius et al, 1999). Epidemiological studies have revealed that stress or emotional trauma is associated with increases in the risk to develop depression, particularly when experienced early in life (Agid et al, 2000). In addition, it is estimated that $40-50 \%$ of the risk for the development of depression is genetic, although the specific genes that confer the risk for depression are not yet identified (Nestler et al, 2002). It thus appears that interactions between genetic diathesis and environmental influences across the lifespan together underlie depression vulnerability in most patients (Nestler et al, 2002). One of the major challenges for current research in depression is to understand the mechanisms, by which experience throughout development influences neuronal systems within a genetic window of vulnerability, leading to the pattern of

*Correspondence: Dr CB Nemeroff, Department of Psychiatry and Behavioral Sciences, Emory University School of Medicine, 1639 Pierce Drive, WMB, Suite 4000, Atlanta, GA 30322, USA, Tel: 4047278382 , Fax: 404727 3233, E-mail: cnemero@emory.edu

Received I4 July 2003; revised 01 December 2003; accepted 31 December 2003

Online publication: 5 January 2004 at http://www.acnp.org/citations/ Npp0 0504033 10/default.pdf neurobiological and behavioral expressions that is the clinical phenotype of depression.

In this brief review, we summarize the importance of studying the contributions of early adverse experience to the neurobiology of depression. Studying these contributions is important for at least three major reasons: First, there is substantial evidence that early-life stress (ELS) leads to persistent neurobiological adaptations that resemble findings in depression, leading towards an understanding of the relationship of the pathophysiology of depression to the neurobiology of stress. Second, not all depression is related to ELS, and there are clearly important subgroups of depression that are biologically distinct. Previous research on the neurobiology of depression has likely been significantly confounded by a lack of consideration of early-life stress. Third, identifying neurobiological subtypes of depression in relation to developmental pathways may have manifold implications for designing effective treatments for depression and for predicting treatment response. In the space below, the evidence underscoring the relevance of these considerations is summarized.

\section{EVIDENCE FOR A ROLE OF ELS IN THE PATHOPHYSIOLOGY OF DEPRESSION}

\section{Relationship Between ELS and Depression}

The most salient forms of ELS in humans are sexual, physical, and emotional maltreatment, as well as parental loss. Other forms of ELS include accidents, surgeries and chronic illness, natural disasters, war and terrorism-related 
events, as well as less evident experiences, such as unstable families, inadequate parental care due to mental or physical illness, dysfunctional relationships between parent and child, and poverty. Any such situation occurring within a defined developmental period (eg before the onset of sexual maturation) may be classified as ELS in humans. Human ELS typically occurs as chronic or ongoing adversity and various forms of ELS often coexist (Heim et al, 2003).

Considerable evidence from a variety of studies suggests that ELS increases the risk for depression. One study comprised of almost 2000 women revealed that those with a history of childhood sexual or physical abuse exhibited more symptoms of depression and anxiety and had more frequently attempted suicide than women without a history of childhood abuse (McCauley et al, 1997). Women who have been abused in childhood are four times more likely to develop syndromal major depression in adulthood than women who have not been abused, and the magnitude of the abuse is correlated with the severity of depression (Mullen et al, 1996). Childhood abuse has also been associated with earlier-onset and more chronic depression (Heim and Nemeroff, 2001). In addition, parental loss predominantly due to parental separation has also been found to increase the risk for major depression in casecontrol and epidemiological studies (Agid et al, 1999). Twin studies have provided concordant findings (Kendler et al, 1992, 1993, 2002).

Multiple factors may influence the manifestation of depression in relation to ELS. Thus, women are more likely to develop major depression after ELS than men (Weiss et al, 1999). There is also recent evidence that genetic variations moderate the effects of ELS on depression (Caspi et al, 2003). The effects of ELS on depression appear to be mediated in part by the extent to which the events cause family disruption or dysfunction (Agid et al, 2000). Episodes of depression in adulthood are often exacerbated by ongoing stress (Kendler et al, 1992), suggesting that ELS induces sensitization to subsequent stress, which, in interaction with other risk factors, predisposes individuals to develop depression. It should be noted that depression is surely not the sole consequence of ELS, but ELS is associated with multiple other psycho- and physiopathological states that often coexist with depression and are exacerbated or aggravated by stress (reviewed in Agid et al, 2000; Heim and Nemeroff, 2001).

\section{Neurobiology of ELS}

The pronounced effects of ELS on health and adaptation throughout the lifespan are believed to be mediated by the substantial plasticity of the developing central nervous system (CNS) as a function of experience. During such critical periods, certain brain regions are also particularly sensitive to adverse experiences, which may then lead to major, sometimes irreversible, abnormalities (Weiss and Wagner, 1998). It is, thus, conceivable that stress or emotional trauma during development permanently shapes the brain regions that mediate stress and emotion, leading to altered emotional processing and heightened responsiveness to stress, which in the genetically vulnerable individual may then evolve into psychiatric disorders, such as depression.
One major stress response system that has been closely scrutinized in depression is the hypothalamic-pituitaryadrenal (HPA) axis. Upon exposure to stress, neurons in the hypothalamic paraventricular nucleus (PVN) secrete corticotropin-releasing factor (CRF) from the median eminence into the hypothalamo-hypophyseal portal circulation, which stimulates the production and release of adrenocorticotropin (ACTH) from the anterior pituitary. ACTH in turn stimulates release of glucocorticoids from the adrenal cortex. Several brain pathways modulate HPA axis activity. The hippocampus and the prefrontal cortex (PFC) inhibit the HPA axis, whereas the amygdala and monoaminergic input from the brainstem stimulate PVN CRF neurons. Glucocorticoids exert negative feedback control on the HPA axis by regulating hippocampal and PVN neurons. Sustained glucocorticoid exposure has adverse effects on hippocampal neurons, particularly in the CA3 region, including reduction in dendritic branching, loss of dendritic spines, and impairment of neurogenesis. Glucocorticoid overexposure also adversely affects the PFC. Such damage might progressively reduce inhibitory control of the HPA axis (eg reviewed in Arborelius et al, 1999; Fuchs and Gould, 2000; Nestler et al, 2002). CRF neurons integrate information relevant to stress not only at the hypothalamic PVN, but also in a widespread circuitry throughout the brain. Direct CNS administration of CRF to laboratory animals produces integrated endocrine, autonomic, and behavioral responses that parallel signs of stress, depression, and anxiety. $\mathrm{CRF}_{1}$ receptor antagonists or $\mathrm{CRF}_{1}$ receptor knockouts exhibit attenuated stress responses (eg reviewed in Dunn and Berridge, 1990; Owens and Nemeroff, 1991; Arborelius et al, 1999). Anatomic, pharmacological, and electrophysiological studies provide evidence for an important role of a circuit connecting the amygdala and the hypothalamus with the locus coeruleus (LC) in the brain stem. CRF and norepinephrine (NE) appear to form a feedforward cascade in this circuit, which participates in the regulation of vigilance, anxiety and fear, and the integration of endocrine and autonomic responses. Gamma-aminobutyric acid (GABA) as well as glucocorticoids inhibit this feed-forward cascade. Other neuromodulators, such as neuropeptide Y (NPY) and oxytocin, appear to counteract the effects of CRF in the stress responses (eg reviewed in Koob, 1999; Kaufman et al, 2000; Sánchez et al, 2001; Nestler et al, 2002). Any disruptions in these circuits, as a potential consequence of ELS, may plausibly lead to altered stress reactivity and may underlie the emotional, cognitive, and vegetative changes seen in depression.

Laboratory animal studies have provided direct evidence that ELS indeed leads to heightened stress reactivity and alterations in the aforementioned neural circuits that persist into adulthood. For example, adult rats who were separated from their dams for $180 \mathrm{~min} /$ day on postnatal days 2-14 exhibit up to three-fold increases in ACTH and corticosterone responses to a variety of psychological stressors when compared to control rats (Ladd et al, 2000; Plotsky and Meaney, 1993). These rats also show reduced feedback sensitivity of the HPA axis. Maternally separated rats also develop marked behavioral changes, including increased anxiety-like behavior, anhedonia, alcohol preference, sleep disruption, decreased appetite, and cognitive impairment (Ladd et al, 2000; Huot et al, 2001; PM Plotsky, unpublished 
observations). Similar effects have been observed in adult rats, whose mothers naturally exhibited low maternal care behavior (Liu et al, 1997). Subsequent studies revealed multiple CNS changes that likely underlie physiological and behavioral sensitization to stress after maternal separation or lack of maternal care. These findings include increased activity (increased CRF mRNA expression) and sensitization of CRF neurons in hypothalamic and limbic regions, decreased glucocorticoid receptor density in the hippocampus and PFC, increased MR in the hippocampus, decreased mossy fiber development and neurogenesis in the hippocampus, increased locus coeruleus $\mathrm{NE}$ activity as well as decreased $\mathrm{GABA}_{\mathrm{A}}$ /central benzodiazepine receptor binding, decreased oxytocin receptor binding (in females), and decreased NPY concentrations in selected brain regions (Caldji et al, 1998, 2000; Francis et al, 2002; Huot et al, 2002; Jimenez-Vasquez et al, 2001; Ladd et al, 2000; Liu et al, 1997, 2000; Meaney et al, 1996; Plotsky and Meaney, 1993; Plotsky et al, 2001). Taken together, in rodents, ELS induces manifold changes in multiple neurocircuits that are involved in neuroendocrine, autonomic, and behavioral responses to stress. If similar changes also occurred in humans exposed to ELS, these changes might indeed confer an enhanced risk for depression and anxiety disorders.

It is, however, difficult to infer from studies in rodents to the effects of ELS in humans. In addition to the ontogenetic and neurobiological differences between rodents and primates, there are inherent difficulties in modeling typical stressful experiences of human children in rodent paradigms. Non-human primate paradigms appear more suitable to model ELS and its effects on development in humans. Similar to models in rodents, a number of studies have evaluated the effects of prolonged deprivation or repeated separations of infant non-human primates from their mothers or peers. It is of note that monkey and human infants indeed demonstrate similar acute behavioral and physiological reactions to separations (Sánchez et al, 2001). Interestingly, infant monkeys show robust activation of the right and deactivation of the left frontal cortex in reaction to maternal separation, and the extent of change is corraleted with cortisol increases (Rilling et al, 2001). A similar pattern has been observed in rhesus monkeys with fearful temperament (Kalin et al, 1998). When tested as adults, non-human primates exposed to prolonged periods of maternal or social deprivation exhibit marked behavioral, physiological, and neurobiological changes. These include increased fearfulness and anxiety, social dysfunction, aggression, aberrant stereotypic and self-directed behaviors, altered ingestion and anhedonia, as well as altered neurochemical, immune, and autonomic function (reviewed in Sánchez et al, 2001; Pryce et al, 2002; Gilmer and McKinney, 2003). It remains unclear, however, in what way early deprivation affects the HPA axis in non-human primates. Basal and stress-induced HPA axis activation has been reported to be either increased (Higley et al, 1991, 1992; Fahlke et al, 2000) or reduced (Clarke, 1993). If increased cortisol concentrations were observed, these were positively correlated with alcohol preference (Fahlke et al, 2000). Squirrel monkeys exposed to repeated social separations also demonstrate reduced cortisol responses to later separation stress and increased glucocorticoid feedback sensitivity (Lyons et al, 1999, 2000). Similarly, decreased morning cortisol excretion was recently reported for marmoset monkeys exposed to repeated maternal separation (Dettling et al, 2002). Another paradigm of ELS in nonhuman primates involves exposure of mothers of infant bonnet macaques to unpredictable conditions with respect to food access over 3 months, resulting in diminished perception of security and a reduction of maternal care in the infants. When tested as adults, bonnet macaques reared under this variable foraging demand condition demonstrate elevated cerebrospinal fluid (CSF) CRF concentrations (but low CSF cortisol concentrations), sensitization of the NE system, and behavioral sensitization to fear stimuli (Coplan et al, 1996; Rosenblum et al, 1994, 2002). Thus, ELS appears to result in decreased adrenocortical activity in several nonhuman primate models, paralleling some findings in posttraumatic stress disorder (Yehuda, 2002). It should be noted that these non-human primate models approximate experiences of neglect in human children, but are different from other types of child maltreatment, that is physical and sexual abuse. Interestingly, a spontaneous occurrence of infant physical abuse and neglect has been observed in up to $10 \%$ of non-human primates living in groups (Maestripieri, 1999). Although this naturally occurring abuse might be the closest model of human child maltreatment, its developmental effects in non-human primates have not been studied in detail (Sánchez et al, 2001). Preliminary evidence suggests that HPA axis function is altered in these monkeys (see Maestripieri, 1999).

Several retrospective clinical studies have evaluated the long-term consequences of ELS in adult humans. In parallel to findings in rodents, we found that women abused as children, including those with and those without current depression, exhibit greater plasma ACTH responses to psycho-social laboratory stress than controls. The increase was more pronounced in abused women with current depression, and these women also showed greater cortisol and heart rate responses than controls (Heim et al, 2000). Abused women without current depression also showed increased ACTH responses to CRF stimulation, whereas abused depressed women showed blunted ACTH responses relative to controls. In the ACTH stimulation test, abused women who were not depressed exhibited decreased cortisol responsiveness. Abused women also exhibited decreased basal cortisol concentrations. We interpret these findings as reflecting sensitization of the pituitary and counter-regulative adaptation of the adrenal gland in abused women without current depression. On further stress exposure, such women may then hypersecrete CRF, resulting in depression and pituitary CRF receptor downregulation (Heim et al, 2001). Accordingly, we observed an inverse relationship between CSF CRF concentrations and ACTH responses to CRF in these women (Newport et al, 2003). Similar sensitization to stress has been reported for adults with early parental loss experience (Luecken, 1998). Two recent studies provide evidence that the experience of ELS is associated with increased cortisol escape in the combined dexamethasone-CRF test in adults, suggesting altered feedback properties of the HPA axis (L Carpenter, personal communication; Rinne et al, 2002). Moreover, altered NE and serotonin function has been reported in relation to the experience of ELS (Heim and Nemeroff, 2001). It should be noted that several studies have reported 
similar neuroendocrine and neurochemical changes in abused children, which are reviewed elsewhere (Heim and Nemeroff, 2001). Magnetic resonance imaging (MRI) studies reported decreased hippocampal volumes in adults with various types of ELS (Bremner et al, 1997; McNeil et al, 2000; Stein et al, 1997; Vythilingam et al, 2002). Since hippocampal volume loss is not observed in abused children or young adults (although corpus callosum, amygdala, and cortical development seems to be impaired) (Teicher et al, 2002), some have suggested that repeated bursts of cortisol secretion over the course of time may eventually result in smaller hippocampi. Enhanced CRF secretion during development may also contribute to progressive hippocampal volume loss (Brunson et al, 2001). Positron emission tomography (PET) studies revealed functional changes of frontal cortical regions during mental imagery in abused women with PTSD vs abused women without PTSD (Bremner et al, 1999; Shin et al, 1999). These findings, however, do not inform on potential cortical functional changes due to abuse itself. The concatenation of findings suggests that ELS is associated with long-term neurobiological changes in humans, which are comparable to those described in preclinical studies. These findings may underlie an enhanced risk for psychopathology, including depression.

\section{Comparison of the Neurobiology of ELS and Depression}

Many, but not all, of the neurobiological effects of ELS parallel established features of major depression. Perhaps the most striking similarity involves hyperactivity of CNS CRF systems. Similar to findings in animal models of ELS, depressed patients show increased CSF CRF concentrations (Nemeroff et al, 1984) as well as increased CRF mRNA expression and CRF concentrations in the hypothalamic PVN and the locus coeruleus (Raadsheer et al, 1994, 1995; Bissette et al, 2003). Blunted ACTH responses to CRF stimulation provide indirect evidence for CRF hypersecretion in patients with depression (Holsboer et al, 1984; Gold et al, 1986) and parallel findings of blunted responses in abused women with depression and findings of downregulated pituitary $\mathrm{CRF}$ receptors in maternally separated rats. Escape from cortisol suppression in the combined dexamethasone/CRH test, as recently observed in humans in relation to ELS, is believed to be the most sensitive marker for HPA axis dysfunction in major depression and also detects vulnerability to depression in first-degree relatives of depressed patients (Holsboer et al, 1995). In addition, many other CNS features of depression parallel the effects of ELS. These include noradrenergic and serotonergic dysfunction, decreased GABA and NPY transmission, as well as structural and/or functional changes in brain circuits relevant to stress and emotion, including the hippocampus, PFC, and amygdala. Several newer findings in depression suggest that impairment in neurotrophic mechanisms and alterations in the brain's reward pathways are involved in depression. Impaired neurogenesis has also been reported in rodent models of ELS, whereas little is known on the effects of ELS on motivational and reward pathways (for reviews on the neurobiology of depression, see Arborelius et al, 1999; Nestler et al, 2002). It should be noted that low adrenocortical (re-)activity, as observed in some nonhuman primate models of ELS and in abused women, is dissimilar to the hypercortisolemia that has classically been associated with melancholic major depression, although decreased rather than increased cortisol secretion has been measured in patients with major depression and comorbid PTSD (Oquendo et al, 2003). Concordant with the many obvious biological similarities, ELS induces behavioral changes in animal models that closely parallel symptoms of depression and common comorbid disorders, including anxiety and substance abuse disorders.

Taken together, the specific neurobiological alterations that occur as a consequence of ELS may result in effects that ultimately trigger depression after additional stress: a sensitized feed-forward cascade between the CRF and NE systems, in concert with altered hippocampal function, would drive the HPA axis, resulting in enhanced and sustained cortisol responses, which may cause further brain damage and impairment of neurogenesis, leading to further disinhibition of stress responses. Relative hypocortisolism before a given stressor might have permissive effects towards the activation of central stress responses. Alterations in protective neurotransmitter systems, as a consequence of ELS, may further accelerate this cascade. Sustained CRF and NE effects may lead to despair, sleep disruption, loss of appetite, and anxiety-like behavior. Progressive hippocampal impairment may underlie cognitive deficits. Genetic factors, gender, and other traits might moderate this response cascade. Antidepressants appear to interfere with this cascade of events at various levels (see Heim et al, 2003).

\section{EVIDENCE FOR DIFFERENCES IN THE NEUROBIOLOGY OF DEPRESSION DEPENDING ON THE PRESENCE OR ABSENCE OF ELS}

The increasing insight into the biological effects of ELS and their importance for the development of depression pose a significant problem for the interpretation of previous research on the neurobiology of depression. Given the high prevalence of ELS among depressed patients (and the general population), it is conceivable that previous studies surely included patients (and controls) with significant ELS, but the effects of ELS on biological findings were not separated from those of depression. Depending on the distribution of ELS across patient and control groups, previous findings on the neurobiology of depression might be significantly confounded. For example, Figure 1 shows our previous findings on ACTH responses to psychosocial stress in women (Heim et al, 2000). As shown in Panel a, no significant effects are observed, when subjects are subdivided based on current depression only. However, as shown in panel b, marked group differences emerge, when subjects are subdivided based on both current depression and ELS in a balanced design. Similarly, we recently demonstrated that smaller hippocampi in depression are associated with child abuse and do not occur in depressed women without ELS (Vythilingam et al, 2002). Studies in children provide similar evidence (Kaufman et al, 1997). It appears that many of the established neurobiological findings in depression may indeed be due to ELS, while depression in the absence of ELS is not associated with 

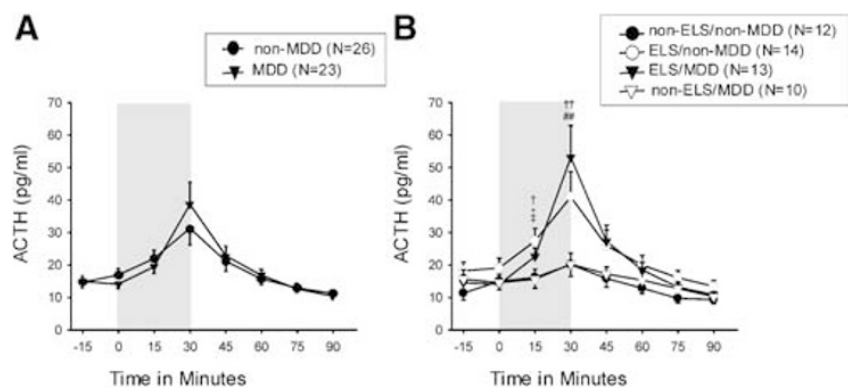

Figure I Mean plasma adrenocorticotropin (ACTH) ( \pm standard errors of the mean) before, during (shaded area), and after a standardized laboratory stressor in adult women. As shown in panel a, no significant differences in response profiles are observed, when women are subdivided based on presence or absence of current major depression only. However, as shown in panel b, marked group differences emerge, when women are subdivided based on presence or absence of both current major depression and reported history of child abuse (two-way analysis of covariance with repeated measures: Group: $\mathrm{F}=3.81, \mathrm{df}=3,44, p=0.02$; Group $\times$ time: $F=4.36, \quad d f=21,308, \quad p<0.001$; covariate ethnicity: $\mathrm{F}=6.68, \mathrm{df}=\mathrm{I}, \mathrm{p}=0.0 \mathrm{I}) .{ }^{\dagger} \mathrm{CON}$ vs ELS/MDD: $p<0.05$, *CON vs ELS/ non-MDD: $p<0.05$, tELS/non-MDD vs non-ELS/MDD: $p<0.05,{ }^{\dagger \dagger} \mathrm{CON}$ vs ELS/MDD: $p<0.01,{ }^{\# \# E L S / M D D ~ v s ~ n o n-E L S / M D D: ~} p<0.01$ Reprinted in part from Heim et al (2000).

stress system changes. It also appears that control groups may be significantly confounded due to ELS. Such confounding may also occur in studies of risk factors for depression. For example, the observed preponderance of women in depression might be due to gender differences in ELS or the response to it (Weiss et al, 1999). Also, symptom patterns of depression as well as comorbidity rates between depression and other disorders, such as substance abuse, might be a function of ELS (Molnar et al, 2001). Neurobiological and symptom patterns as a function of ELS might also span across DSM-IV diagnostic categories.

The classification of depression has long been controversial (eg Parker et al, 1991; Parker, 2000). Historically, a binary model of depression prevailed over many years that distinguished between endogenous/psychotic and reactive/ neurotic subtypes of depression. Unitarian positions, in contrast, assumed that different manifestations of depression are located along a continuum of a single subtype. The proposition of a 'psychobiological final common pathway model' of depression appeared to support the unitarian view (Akiskal and McKinney, 1973). With DSM-III, a purely descriptive classification based on phenomenology was introduced, supposedly representing a research-based medical model rather than a clinically based biopsychosocial model (Wilson, 1993). It has been argued that this current classification has obscured depression research and failed to produce uniform neurobiological findings or predictors of treatment response in depression and that paradigms of depression should be empirically tested using clinical, etiological, and biological variables (see Parker, 2000 for a discussion). Given our findings on different neurobiological subtypes of depression, depending on ELS, we suggest that ELS should be considered when deriving depression models. Other findings showing that ELS is associated with differences in onset, course, and clinical manifestation of depression further substantiate the need to consider ELS in depression models (Young et al, 1997; Bernet and Stein, 1999; Brodaty et al, 2001). A new typology of depression, based on developmental pathways and neurobiological patterns, might indeed lead towards improved treatment and the identification of predictors of treatment response.

\section{ELS AND THE TREATMENT RESPONSE IN DEPRESSION}

The evidence for a role of ELS in the pathophysiology of depression, as well as the evidence for neurobiologically different subtypes of depression depending on the presence or absence of ELS, has seminal implications for research and practice regarding the treatment of depression. In other words, depressed patients with ELS may respond to different treatments than depressed patients without early ELS experience. Indeed, there is evidence that ELS moderates the response to pharmacological treatment in dysthymia and depression (Hayden and Klein, 2001; Kaplan and Klinetob, 2000). Childhood adversity has also been related to higher likelihood of relapse after initial remission of depression (Lara et al, 2000). We recently evaluated whether the presence or absence of ELS might moderate treatment responses of patients with chronic depression to either pharmacological treatment (nefazodone) or psychotherapy (Cognitive Behavioral Analysis System of Psychotherapy; see McCullough, 2003), or the combination of both (Nemeroff et al, 2003). Overall, the effects of the antidepressant alone and psychotherapy alone were equal and significantly less effective than combination treatment (Keller et al, 2000). When stratifying patients according to the presence or absence of ELS, we found that those with ELS (ie parental loss, physical abuse, sexual abuse, or neglect) showed a superior response to psychotherapy alone compared to the antidepressant. Moreover, the combination of psychotherapy and pharmacotherapy was only marginally superior to psychotherapy alone among the ELS cohort. Our results suggest that psychotherapy may be an essential element in the treatment of depression associated with ELS (Nemeroff et al, 2003).

Indeed, there are few predictors of response to any particular treatment in depression to date. Our results suggest that consideration of ELS might be useful in directing treatment decisions in clinical care. Differences in treatment responses as a function of ELS might occur due to different neurobiological pathways to depression, which might be differentially affected by different classes of drugs or even psychotherapy. Interestingly, there is evidence from PET studies that depressed patients who respond to cognitive behavioral therapy have different brain activation patterns before the treatment as compared to depressed patients who respond to pharmacological treatment (Mayberg, 2003). Future studies should evaluate whether ELS is associated with such 'treatment response-specific' neuronal activation patterns. Identification of etiological and neurobiological predictors of treatment response might also help deriving a new typology of depressive disorders.

Future studies should further evaluate whether ELS predicts normalization of HPA and neuronal abnormalities, together with symptomatic improvement, in response to different treatment regimens in depression. Indeed, little is known to date as to whether certain treatments can alter or reverse the neurobiological consequences of ELS. One 
recent study showed that treatment with fluvoxamine, a selective serotonin-reuptake inhibitor, reversed HPA axis hyper-responsiveness in the dexamethasone/CRF test, particularly in those borderline personality disordered patients who reported sustained histories of child abuse, independent of symptomatic status (Rinne et al, 2003). In order to improve treatment of depression, it will probably be imperative to develop treatment strategies that directly target the differential etiological and neurobiological pathways to depression. Drugs that directly target the neuronal circuits and mechanisms that are modified by ELS, such as $\mathrm{CRF}$ receptor antagonists, might be particularly effective in the treatment or prevention of depression related to ELS, in addition to psychotherapy.

\section{CONCLUSION}

We have described the relationship between ELS and depression. ELS induces persistent changes in neurobiological stress response systems, which might reflect a biological priming for the development of depression especially after additional stress exposure. Other risk factors, such as genetic disposition and female gender, may interfere with components of the stress response and thereby further increase vulnerability to depression in relation to ELS. We have also shown that there may be important subgroups of depression that are biologically distinct, dependent on the presence or absence of ELS, suggesting that previous research on the neurobiology of depression might have been significantly confounded by lack of consideration of ELS. Finally, the identification of neurobiological subtypes of depression in relation to developmental pathways might have paramount implications for designing effective treatments for depression. Future research should elucidate the interactions of between genetic dispositions and environmental factors throughout the lifespan in shaping neurobiological phenotypes with vulnerability to depression. It might be necessary in the future to re-evaluate current approaches to the classification of depressive disorders. For instance, the purely descriptive classification of depression in DSM-IV is insufficient to capture subtypes of depression with differential developmental pathways and neurobiological patterns. New typologies that address developmental pathways, neurobiological patterns and associated symptom constellations might significantly accelerate research progress on the causes of depression and ultimately lead to optimized and effective clinical care.

The financial disclosure is detailed in the supplementary document.

\section{ACKNOWLEDGEMENTS}

This work is in part supported by NIMH Grants MH-42088 and the Conte Center for the Psychobiology of Mood Disorders (MH-58922), as well as a NARSAD Young Investigator Award to $\mathrm{CH}$.

\section{REFERENCES}

Agid O, Kohn Y, Lerer B (2000). Environmental stress and psychiatric illness. Biomed Pharmacother 54: 135-145.
Agid O, Shapira B, Zislin J, Ritsner M, Hanin B, Murad H et al (1999). Environment and vulnerability to major psychiatric illness: a case control study of early parental loss in major depression, bipolar disorder and schizophrenia. Mol Psychiatry 4: $163-172$.

Akiskal HS, McKinney WT (1973). Depressive disorders: toward a unified hypothesis. Science 182: 20-29.

Arborelius L, Owens MJ, Plotsky PM, Nemeroff CB (1999). The role of corticotropin-releasing factor in depression and anxiety disorders. J Endocrinol 160: 1-12.

Bernet CZ, Stein MB (1999). Relationship of childhood maltreatment to the onset and course of major depression in adulthood. Depress Anxiety 9: 169-174.

Bissette G, Klimek V, Pan J, Stockmeier C, Ordway G (2003). Elevated concentrations of CRF in the locus coeruleus of depressed subjects. Neuropsychopharmacology 28: 1328-1335.

Bremner JD, Narayan M, Staib LH, Southwick SM, McGlashan T, Charney DS (1999). Neural correlates of memories of childhood sexual abuse in women with and without posttraumatic stress disorder. Am J Psychiatry 156: 1787-1795.

Bremner JD, Randall P, Vermetten E, Staib L, Bronen RA, Mazure $C$ et al (1997). Magnetic resonance imaging-based measurement of hippocampal volume in posttraumatic stress disorder related to childhood physical and sexual abuse. Biol Psychiatry 41: 23-32.

Brodaty H, Luscombe G, Parker G, Wilhelm K, Hickie I, Austin MP et al (2001). Early and late onset depression in old age: different aetiologies, same phenomenology. J Affect Disord 66: 225-236.

Brunson KL, Eghbal-Ahmadi M, Bender R, Chen Y, Baram TZ (2001). Long-term, progressive hippocampal cell loss and dysfunction induced by early-life administration of corticotropin-releasing hormone reproduce the effects of early-life stress. Proc Natl Acad Sci USA 98: 8856-8861.

Caldji C, Francis D, Sharma S, Plotsky PM, Meaney MJ (2000). The effects of early rearing environment on the development of GABAA and central benzodiazepine receptor levels and noveltyinduced fearfulness in the rat. Neuropsychopharmacology 22: 219-229.

Caldji C, Tannenbaum B, Sharma S, Francis D, Plotsky PM, Meaney MJ (1998). Maternal care during infancy regulates the development of neural systems mediating the expression of fearfulness in the rat. Proc Natl Acad Sci USA 95: 5335-5340.

Caspi A, Sugden K, Moffitt TE, Taylor A, Craig IW, Harrington H et al (2003). Influence of life stress on depression: moderation by a polymorphism in the 5-HTT gene. Science 301: 386-389.

Clarke AS (1993). Social rearing effects on HPA axis activity over early development and in response to stress in rhesus monkeys. Dev Psychobiol 26: 433-446.

Coplan JD, Andrews MW, Rosenblum LA, Owens MJ, Friedman S, Gorman JM et al (1996). Persistent elevations of cerebrospinal fluid concentrations of corticotropin-releasing factor in adult nonhuman primates exposed to early-life stressors: implications for the pathophysiology of mood and anxiety disorders. Proc Natl Acad Sci USA 93: 1619-1623.

Dettling AC, Feldon J, Pryce CR (2002). Repeated parental deprivation in the infant common marmoset (Callithrix jacchus, primates) and analysis of its effects on early development. Biol Psychiatry 52: 1037-1046.

Dunn AJ, Berridge CW (1990). Physiological and behavioral responses to corticotropin-releasing factor administration: is CRF a mediator of anxiety or stress responses? Brain Res Brain Res Rev 15: 71-100.

Fahlke C, Lorenz JG, Long J, Champoux M, Suomi SJ, Higley JD (2000). Rearing experiences and stress-induced plasma cortisol as early risk factors for excessive alcohol consumption in nonhuman primates. Alcohol Clin Exp Res 24: 644-650.

Francis DD, Young LJ, Meaney MJ, Insel TR (2002). Naturally occurring differences in maternal care are associated with the 
expression of oxytocin and vasopressin receptors: gender differences. J Neuroendocrinol 14: 349-353.

Fuchs E, Gould E (2000). Mini-review: in vivo neurogenesis in the adult brain: regulation and functional implications. Eur $J$ Neurosci 12: 2211-2214.

Gilmer WS, McKinney WT (2003). Early experience and depressive disorders: human and non-human primate studies. $J$ Affect Disord 75: 97-113.

Gold PW, Loriaux DL, Roy A, Kling MA, Calabrese JR, Kellner CH et al (1986). Responses to corticotropin-releasing hormone in the hypercortisolism of depression and Cushing's disease. Pathophysiologic and diagnostic implications. $N$ Engl J Med 314: 1329-1335.

Hayden EP, Klein DN (2001). Outcome of dysthymic disorder at 5year follow-up: the effect of familial psychopathology, early adversity, personality, comorbidity, and chronic stress. Am J Psychiatry 158: 1864-1870.

Heim C, Meinlschmidt G, Nemeroff CB (2003). Neurobiology of early-life stress. Psych Ann 33: 1-10.

Heim C, Nemeroff CB (2001). The role of childhood trauma in the neurobiology of mood and anxiety disorders: preclinical and clinical studies. Biol Psychiatry 49: 1023-1039.

Heim C, Newport DJ, Bonsall R, Miller AH, Nemeroff CB (2001). Altered pituitary-adrenal axis responses to provocative challenge tests in adult survivors of childhood abuse. Am J Psychiatry 158: 575-581.

Heim C, Newport DJ, Heit S, Graham YP, Wilcox M, Bonsall R et al (2000). Pituitary-adrenal and autonomic responses to stress in women after sexual and physical abuse in childhood. JAMA 284: 592-597.

Higley JD, Hasert MF, Suomi SJ, Linnoila M (1991). Nonhuman primate model of alcohol abuse: effects of early experience, personality, and stress on alcohol consumption. Proc Natl Acad Sci USA 88: 7261-7265.

Higley JD, Suomi SJ, Linnoila M (1992). A longitudinal assessment of CSF monoamine metabolite and plasma cortisol concentrations in young rhesus monkeys. Biol Psychiatry 32: 127-145.

Holsboer F, Lauer CJ, Schreiber W, Krieg JC (1995). Altered hypothalamic-pituitary-adrenocortical regulation in healthy subjects at high familial risk for affective disorders. Neuroendocrinology 62: 340-347.

Holsboer F, Von Bardeleben U, Gerken A, Stalla GK, Muller OA (1984). Blunted corticotropin and normal cortisol response to human corticotropin-releasing factor in depression. $N$ Engl J Med 311: 1127.

Huot RL, Plotsky PM, Lenox RH, McNamara RK (2002). Neonatal maternal separation reduces hippocampal mossy fiber density in adult Long Evans rats. Brain Res 950: 52-63.

Huot RL, Thrivikraman KV, Meaney MJ, Plotsky PM (2001). Development of adult ethanol preference and anxiety as a consequence of neonatal maternal separation in Long Evans rats and reversal with antidepressant treatment. Psychopharmacology 158: $366-373$.

Jimenez-Vasquez PA, Mathe AA, Thomas JD, Riley EP, Ehlers CL (2001). Early maternal separation alters neuropeptide $Y$ concentrations in selected brain regions in adult rats. Brain Res Dev Brain Res 131: 149-152.

Kalin NH, Larson C, Shelton SE, Davidson RJ (1998). Asymmetric frontal brain activity, cortisol, and behavior associated with fearful temperament in rhesus monkeys. Behav Neurosci 112: 286-292.

Kaplan MJ, Klinetob NA (2000). Childhood emotional trauma and chronic posttraumatic stress disorder in adult outpatients with treatment-resistant depression. J Nerv Ment Dis 188: 596-601.

Kaufman J, Birmaher B, Perel J, Dahl RE, Moreci P, Nelson B et al (1997). The corticotropin-releasing hormone challenge in depressed abused, depressed nonabused, and normal control children. Biol Psychiatry 42: 669-679.
Kaufman J, Plotsky PM, Nemeroff CB, Charney DS (2000). Effects of early adverse experiences on brain structure and function: clinical implications. Biol Psychiatry 48: 778-790.

Keller MB, McCullough JP, Klein DN, Arnow B, Dunner DL, Gelenberg AJ et al (2000). A comparison of nefazodone, the cognitive behavioral-analysis system of psychotherapy, and their combination for the treatment of chronic depression. $N$ Engl J Med 342: 1462-1470.

Kendler KS, Gardner CO, Prescott CA (2002). Toward a comprehensive developmental model for major depression in women. Am J Psychiatry 159: 1133-1145.

Kendler KS, Kessler RC, Neale MC, Heath AC, Eaves LJ (1993). The prediction of major depression in women: toward an integrated model. Am J Psychiatry 150: 1139-1148.

Kendler KS, Neale MC, Kessler RC, Heath AC, Eaves LJ (1992). Childhood parental loss and adult psychopathology in women. A twin perspective. Arch Gen Psychiatry 49: 109-116.

Koob GF (1999). Corticotropin-releasing factor, norepinephrine, and stress. Biol Psychiatry 46: 1167-1180.

Ladd CO, Huot RL, Thrivikraman KV, Nemeroff CB, Meaney MJ, Plotsky PM (2000). Long-term behavioral and neuroendocrine adaptations to adverse early experience. Prog Brain Res 122: 81-103.

Lara ME, Klein DN, Kasch KL (2000). Psychosocial predictors of the short-term course and outcome of major depression: a longitudinal study of a nonclinical sample with recent-onset episodes. J Abnorm Psychol 109: 644-650.

Liu D, Caldji C, Sharma S, Plotsky PM, Meaney MJ (2000). Influence of neonatal rearing conditions on stress-induced adrenocorticotropin responses and norepinepherine release in the hypothalamic paraventricular nucleus. J Neuroendocrinol 12: 5-12.

Liu D, Diorio J, Tannenbaum B, Caldji C, Francis D, Freedman A et al (1997). Maternal care, hippocampal glucocorticoid receptors, and hypothalamic-pituitary-adrenal responses to stress. Science 277: 1659-1662.

Luecken LJ (1998). Childhood attachment and loss experiences affect adult cardiovascular and cortisol function. Psychosom Med 60: 765-772.

Lyons DM, Martel FL, Levine S, Risch NJ, Schatzberg AF (1999). Postnatal experiences and genetic effects on squirrel monkey social affinities and emotional distress. Horm Behav 36: 266-275.

Lyons DM, Yang C, Mobley BW, Nickerson JT, Schatzberg AF (2000). Early environmental regulation of glucocorticoid feedback sensitivity in young adult monkeys. J Neuroendocrinol 12: 723-728.

Maestripieri D (1999). The biology of human parenting: insights from nonhuman primates. Neurosci Biobehav Rev 23: 411-422.

Mayberg HS (2003). Modulating dysfunctional limbic-cortical circuits in depression: towards development of brain-based algorithms for diagnosis and optimised treatment. $\mathrm{Br}$ Med Bull 65: 193-207.

McCauley J, Kern DE, Kolodner K, Dill L, Schroeder AF, DeChant HK et al (1997). Clinical characteristics of women with a history of childhood abuse. JAMA 277: 1362-1368.

McCullough Jr JP (2003). Treatment for chronic depression using Cognitive Behavioral Analysis System of Psychotherapy (CBASP). J Clin Psychol 59: 833-846.

McNeil TF, Cantor-Graae E, Weinberger DR (2000). Relationship of obstetric complications and differences in size of brain structures in monozygotic twin pairs discordant for schizophrenia. Am J Psychiatry 157: 203-212.

Meaney MJ, Diorio J, Francis D, Widdowson J, LaPlante P, Caldji C et al (1996). Early environmental regulation of forebrain glucocorticoid receptor gene expression: implications for adrenocortical responses to stress. Dev Neurosci 18: 49-72.

Molnar BE, Buka SL, Kessler RC (2001). Child sexual abuse and subsequent psychopathology: results from the National Comorbidity Survey. Am J Public Health 91: 753-760. 
Mullen PE, Martin JL, Anderson JC, Romans SE, Herbison GP (1996). The long-term impact of the physical, emotional, and sexual abuse of children: a community study. Child Abuse Negl 20: 7-21.

Nemeroff CB, Heim CM, Thase ME, Klein DN, Rush AJ, Schatzberg AF et al (2003). Differential responses to psychotherapy versus pharmacotherapy in patients with chronic forms of major depression and childhood trauma. Proc Natl Acad Sci USA, November 13 (Epub ahead of print).

Nemeroff CB, Widerlöv E, Bissette G, Walleus H, Karlsson I, Eklund $\mathrm{K}$ et al (1984). Elevated concentrations of CSF corticotropin-releasing factor-like immunoreactivity in depressed patients. Science 226: 1342-1344.

Nestler EJ, Barrot M, DiLeone RJ, Eisch AJ, Gold SJ, Monteggia LM (2002). Neurobiology of depression. Neuron 34: 13-25.

Newport DJ, Heim C, Owens MJ, Ritchie JC, Ramsey C, Plott S et al (2003). CSF CRF and AVP concentrations predict endocrine responses to pharmaciological challenge. Neuropsychopharmacology 28: 569-576.

Oquendo MA, Echavarria G, Galfalvy HC, Grunebaum MF, Burke A, Barrera A et al (2003). Lower cortisol levels in depressed patients with comorbid post-traumatic stress disorder. Neuropsychopharmacology 28: 591-598.

Owens MJ, Nemeroff CB (1991). Physiology and pharmacology of corticotropin-releasing factor. Pharmacol Rev 43: 425-473.

Parker G (2000). Classifying depression: should paradigms lost be regained? Am J Psychiatry 157: 1195-1203.

Parker G, Hall W, Boyce P, Hadzi-Pavlovic D, Mitchell P, Wilhelm $\mathrm{K}$ et al (1991). Depression sub-typing: unitary, binary or arbitrary? Aust N Z J Psychiatry 25: 63-76.

Plotsky PM, Meaney MJ (1993). Early, postnatal experience alters hypothalamic corticotropin-releasing factor (CRF) mRNA, median eminence CRF content and stress-induced release in adult rats. Mol Brain Res 18: 195-200.

Plotsky PM, Sánchez MM, Levine S (2001). Intrinsic and extrinsic factors modulating physiological coping systems during development. In: Broom DM (ed). Coping with Challenge. Dahlem University Press: Berlin. pp 169-196.

Pryce CR, Ruedi-Bettschen D, Dettling AC, Feldon J (2002). Early life stress: long-term physiological impact in rodents and primates. News Physiol Sci 17: 150-155.

Raadsheer FC, Hoogendijk WJ, Stam FC, Tilders FJ, Swaab DF (1994). Increased numbers of corticotropin-releasing hormone expressing neurons in the hypothalamic paraventricular nucleus of depressed patients. Neuroendocrinology 60: 436-444.

Raadsheer FC, van Heerikhuize JJ, Lucassen PJ, Hoogendijk WJ, Tilders FJ, Swaab DF (1995). Corticotropin-releasing hormone mRNA levels in the paraventricular nucleus of patients with Alzheimer's disease and depression. Am J Psychiatry 152: 1372-1376.

Rilling JK, Winslow JT, O'Brien D, Gutman DA, Hoffman JM, Kilts CD (2001). Neural correlates of maternal separation in rhesus monkeys. Biol Psychiatry 49: 146-157.
Rinne T, De Kloet ER, Wouters L, Goekoop J, De Rijk RH, van den Brink W (2003). Fluvoxamine reduces responsiveness of HPA axis in adult female BPD patients with a history of sustained childhood abuse. Neuropsychopharmacology 28: 126-132.

Rinne T, de Kloet ER, Wouters L, Goekoop JG, DeRijk RH, van den Brink W (2002). Hyperresponsiveness of hypothalamic-pituitary-adrenal axis to combined dexamethasone/corticotropinreleasing hormone challenge in female borderline personality disorder subjects with a history of sustained childhood abuse. Biol Psychiatry 52: 1102-1112.

Rosenblum LA, Coplan JD, Friedman S, Bassoff T, Gorman JM, Andrews MW (1994). Adverse early experiences affect noradrenergic and serotonergic functioning in adult primates. Biol Psychiatry 35: 221-227.

Rosenblum LA, Forger C, Noland S, Trost RC, Coplan JD (2002). Response of adolescent bonnet macaques to an acute fear stimulus as a function of early rearing conditions. Dev Psychobiol 39: 40-45.

Sánchez MM, Ladd CO, Plotsky PM (2001). Early adverse experience as a developmental risk factor for later psychopathology: evidence from rodent and primate models. Dev Psychopathol 13: 419-449.

Shin LM, McNally RJ, Kosslyn SM, Thompson WL, Rauch SL, Alpert NM et al (1999). Regional cerebral blood flow during script-driven imagery in childhood sexual abuse-related PTSD: a PET investigation. Am J Psychiatry 156: 575-584.

Stein MB, Koverola C, Hanna C, Torchia MG, McClarty B (1997) Hippocampal volume in women victimized by childhood sexual abuse. Psychol Med 27: 951-959.

Teicher MH, Andersen SL, Polcari A, Anderson CM, Navalta CP (2002). Developmental neurobiology of childhood stress and trauma. Psychiatr Clin North Am 25: 397-426.

Vythilingam M, Heim C, Newport J, Miller AH, Vermetten E, Anderson $\mathrm{E}$ et al (2002). Childhood trauma associated with smaller hippocampal volume in women with major depression. Am J Psychiatry 159: 2072-2080.

Weiss EL, Longhurst JG, Mazure CM (1999). Childhood sexual abuse as a risk factor for depression in women: psychosocial and neurobiological correlates. Am J Psychiatry 156: 816-828.

Weiss MJ, Wagner SH (1998). What explains the negative consequences of adverse childhood experiences on adult health? Insights from cognitive and neuroscience research. Am J Prev Med 14: 356-360.

Wilson M (1993). DSM-III and the transformation of American psychiatry: a history. Am J Psychiatry 150: 399-410.

Yehuda R (2002). Current status of cortisol findings in post-traumatic stress disorder. Psychiatr Clin North Am 25: 341-368.

Young EA, Abelson JL, Curtis GC, Nesse RM (1997). Childhood adversity and vulnerability to mood and anxiety disorders. Depress Anxiety 5: 66-72.

Supplementary Information accompanies the paper on Neuropsychopharmacology website ( http://www.nature.com/npp). 